\section{Kidney \\ Blood Pressure Research}

Kidney Blood Press Res 2015;40:121-129

DOI: $10.1159 / 000368488$

Published online: March 19, 2015

Accepted: February 13, 2015

This is an Open Access article licensed under the terms of the Creative Commons AttributionNonCommercial 3.0 Unported license (CC BY-NC) (www.karger.com/OA-license), applicable to the online version of the article only. Distribution permitted for non-commercial purposes only.

\title{
Indoxyl Sulfate, Not P-Cresyl Sulfate, is Associated with Advanced Glycation end Products in Patients on Long-Term Hemodialysis
}

\author{
Cheng-Jui Lin ${ }^{a, b, c} \quad J a c k s o n L^{a}{ }^{a} \quad$ Chi-Feng Pan ${ }^{a, b} \quad$ Chih-Kuang Chuang ${ }^{c, d, e}$ \\ Hsuan-Liang Liue Fang-Ju Sun ${ }^{b, f} \quad$ Tuan-Jen Wang ${ }^{g}$ Han-Hsiang Chen ${ }^{a, b}$ \\ Chih-Jen Wu $\mathrm{u}^{\mathrm{a}, \mathrm{b}, \mathrm{h}}$
}

aDivision of Nephrology, Department of Internal Medicine, Mackay Memorial Hospital, Taipei and Hsin-Chu; ${ }^{b}$ Mackay Junior College of Medicine, Nursing and Management; ' Institute of Biotechnology, National Taipei University of Technology; 'Division of Genetics and Metabolism, Department of Medical Research, Mackay Memorial Hospital; eInstitute of Biotechnology, National Taipei University of Technology; ${ }^{\mathrm{f}}$ Department of Medical Research; ${ }^{9}$ Department of Laboratory Medicine, Mackay Memorial Hospital; ${ }^{\mathrm{h}}$ Graduate Institute of Medical Science, Taipei Medical University, Taipei, Taiwan

\section{Key Words}

Indoxyl sulfate $\cdot$ P-cresyl sulfate $\cdot$ Advanced glycation end products $\bullet$ Hemoadialysis

\begin{abstract}
Background/Aims: Advanced glycation end products (AGEs) are pro-inflammatory and prooxidative compounds that play a critical role in endothelial dysfunction and atherosclerosis. Protein-bound uremic toxins, indoxyl sulfate (IS) and p-cresyl sulfate (PCS), inhibit endothelial function. We explored the association of IS and PCS with AGEs in a hemodialysis (HD) cohort. Methods: This study was a cross-sectional study that recruited 129 stable patients on maintenance HD in a single medical center from July 1 to July 15, 2011. Serum levels of total and free IS, PCS and AGEs were measured concurrently. General laboratory results and patient background were also investigated. Results: Serum levels of AGEs were associated with total IS $(r=2.7, p<0.01)$ but not total PCS $(r=0.01$, NS), free IS $(r=0.11, N S)$ or free PCS $(r=$ 0.04 , NS) using Pearson's analysis. Multiple linear regression analysis showed that total IS was significantly related to AGEs $(\beta=0.296, p<0.01)$, free IS $(\beta=0.502, p<0.01)$ and creatinine $(\beta=0.294, p<0.01)$. Serum AGEs levels were also independently correlated with diabetes status $(\beta=0.250, p=0.01)$ and total IS $(\beta=0.341, p<0.01)$ concentrations after adjusting for
\end{abstract}

C.-J. Lin and J. Lin contributed equally to this article and thus share first authorship. 


\section{Kidney \\ Blood Pressure Research}

Kidney Blood Press Res 2015;40:121-129

\begin{tabular}{l|l}
\hline DOI: $10.1159 / 000368488$ & (c) 2015 S. Karger AG, Basel
\end{tabular}

Published online: March 19, 2015

www.karger.com/kbr

other confounding variables. Moreover, patients with diabetes had higher serum AGEs levels than patients without diabetes $(p<0.01)$. Conclusions: These findings suggest that serum levels of total IS were associated with AGEs levels, which may participate in the process of atherosclerosis.

Copyright $\odot 2015$ S. Karger AG, Basel

\section{Introduction}

Uremic compounds are a cause and consequence of chronic kidney disease (CKD). Accumulation of these toxins consequent to the progressive deterioration of kidney function in CKD has a deleterious effect on the cardiovascular system [1], and cardiovascular disease (CVD) remains the leading cause of morbidity and mortality in CKD patients [2,3].

Endothelial cell injury and dysfunction are critical steps in the development and progression of atherosclerosis, which can result of oxidative stress, chronic inflammation and reactive oxygen species (ROS) production in CKD [4, 5]. Previous data suggested that some uremic toxins, including indoxyl sulfate (IS) and p-cresyl sulfate (PCS), which are two protein-bound uremic toxins that originate from the intestinal tract following the metabolism of aromatic amino acids by the intestinal flora, inhibit endothelial proliferation, which may contribute to endothelial cell dysfunction [4, 6]. Evidence from an in vitro study also showed that IS and PCS induce ROS production [5]. Clinical studies in CKD patients on hemodialysis (HD) confirm that these two toxins are valuable surrogate markers of infection [7] and cardiovascular and all-cause mortality [8-10].

Advanced glycation end products (AGEs), pro-inflammatory and pro-oxidative compounds are produced through the non-enzymatic glycation and oxidation of proteins, lipids and nucleic acids [11, 12], and these factors accumulate in CKD patients [13, 14]. Previous studies showed that AGEs were involved in the pathogenesis of CVD via receptorindependent and receptor-dependent pathways $[15,16]$. Therefore, AGEs likely play an important role in the pathogenesis of CVD in these subjects.

These results suggest that protein-bound uremic toxins and AGEs contribute to the high prevalence of cardiovascular mortality in CKD patients. However, the relationship between protein-bound uremic toxins and AGEs is not fully understood.

This cross-sectional study elucidated the correlation of IS and PCS with selected AGEs and other independent variables in a maintenance HD cohort.

\section{Materials and Methods}

\section{Subjects}

This study recruited 129 patients on maintenance HD ( 4 h dialysis, 3 times a week) from a single medical center. The exclusion criteria included subjects with acute infection, liver cirrhosis and malignancy, or patients who were younger than 18 years. Dialyzers with a synthetic dialysis membrane (polysulfone or polyamide) were not reused in any patient. Dialysis efficiency was calculated according to Kidney Disease Outcomes Quality Initiative (KDOQI) guidelines, and single-pool Kt/V of urea nitrogen was calculated [17]. Residual renal function was estimated from an interdialytic urine collection, and the results are expressed as weekly renal Kt/V. The normalized protein catabolic rate (nPCR; g/kg/d) was measured for daily protein intake. The study was performed according to the principles of the Declaration of Helsinki, and the ethics committee of the Mackay Memorial Hospital approved the study. All patients signed informed consent was signed before the study.

\section{Laboratory Assessments}

Blood samples of patients were taken after enrollment immediately before the HD session 2 times per week (second and third session). The following biochemical parameters were measured: blood urea nitrogen, creatinine $(\mathrm{Cr})$, hemoglobin $(\mathrm{Hb})$, hematocrit $(\mathrm{Hct})$, potassium $(\mathrm{K})$, calcium $(\mathrm{Ca})$, phosphate $(\mathrm{P})$, 


\section{Kidney \\ Blood Pressure Research}

Kidney Blood Press Res 2015;40:121-129

\begin{tabular}{l|l}
\hline DOI: $10.1159 / 000368488$ & C 2015 S. Karger AG, Basel
\end{tabular}

Published online: March 19, 2015

www.karger.com/kbr bicarbonate, high sensitivity C-reactive protein (hsCRP), intactparathyroid hormone (i-PTH), alkaline phosphatase, albumin, total IS, free IS, total PCS, free PCS and AGEs. The bromocresol green method was used to determine albumin content. Serum levels of hsCRP were measured using a Behring Nephelometer II (Dade Behring, Tokyo, Japan). AGE concentrations were measured using ELISA kits (AGEs Immunoassay, Hanson Biomedical, Taipei, Taiwan). All levels of serum PCS and IS were measured twice weekly to obtain an average value. Other biochemistry parameters were measured before the second HD session during the same week.

Serum IS and PCS were analyzed using LC-MS/MS (4000 QTRAP, USA). Briefly, serum samples were prepared and deproteinized by heat denaturation. HPLC was performed at room temperature using a dC18 column $(3.0 \times 50 \mathrm{~mm}$, Atlantis, Waters). The buffers used were (A) $0.1 \%$ formic acid and (B) 1 $\mathrm{mM} \mathrm{NH}_{4} \mathrm{OAc}+0.1 \%$ formic acid in $100 \%$ acetonitrile. The flow rate was $0.6 \mathrm{~mL} / \mathrm{min}$ with a 3.5-min gradient cycling from $90 \%$ A/10\% B to $10 \%$ A/90\% B. PCS and IS were eluted at 2.73 and $2.48 \mathrm{~min}$, respectively, under these conditions. Standard curves for PCS and IS were set at 1, 5, 10, 50, 250, 500 and $1000 \mu \mathrm{g} / \mathrm{L}$. PCS and IS standards were processed in the same manner as the serum samples, and the standards correlated with the serum samples with an average $r^{2}$ value of $0.996 \pm 0.003$. Samples were diluted if the IS or PCS concentration exceeded the standard curve. Quantitative results were obtained, and concentrations $(\mathrm{mg} / \mathrm{L})$ were calculated. The sensitivity of this assay was $1 \mu \mathrm{g} / \mathrm{L}$ for PCS and $1 \mu \mathrm{g} / \mathrm{L}$ for IS.

\section{Statistical Analysis}

The demographic data are expressed as the means \pm standard deviation. Pearson's correlation coefficient or Spearman's rank correlation were used to analyze the relationship between serum IS, PCS and selected clinical or biochemical variables. Stepwise multiple linear regression analysis was used for total IS or AGEs as a dependent variable to assess the influence of the tested parameters. A receiveroperating characteristic (ROC) curve of weight was use to predict serum IS levels (30.7 mg/L). The optimum cut-off point (open circle) was defined as the closest point on the ROC curve to the point $(X, Y)=(0,1)$, where $X=1-$ specificity and $Y=$ sensitivity. Results from the high and low IS groups divided by $30.7 \mathrm{mg} / \mathrm{L}$ and AGEs levels in patients with or without diabetes mellitus were compared using Student's t-tests or the $\chi^{2}$ test. A p-value less than 0.05 was considered statistically significant. All statistical analyses were conducted using the SPSS ver. 17.0 software program (SPSS, Chicago, IL).

\section{Results}

Patient Characteristics

Table 1 shows patient demographics and clinical characteristics. An independent physician screened 160 stable HD patients, and 129 patients were recruited. The etiology of
Table 1. Baseline characteristics of the patients

\begin{tabular}{lc}
\hline & Patient \\
& demographics \\
& HD patients \\
& (n=129) \\
\hline Median age (y) & $65.61 \pm 9.12$ \\
Men & $66(51.2 \%)$ \\
Women & $63(48.8 \%)$ \\
Time of HD (m) & $42.27 \pm 21.47$ \\
Diabetes & $58(45.0 \%)$ \\
PKD & $4(3.1 \%)$ \\
SLE & $2(1.5 \%)$ \\
cGN & $65(50.4 \%)$ \\
HTN & $83(64.3 \%)$ \\
SBP (mmHg) & $146.48 \pm 16.08$ \\
DBP (mmHg) & $86.47 \pm 8.27$ \\
nPCR (g/kg/day) & $1.20 \pm 0.11$ \\
Kt/V & $1.56 \pm 0.24$ \\
rK/V & $12.6 \pm 6.2$ \\
CO2 (mmol/L) & $23.18 \pm 1.65$ \\
Hb (g/dL) & $10.64 \pm 1.04$ \\
Creatinine (mg/dl) & $10.95 \pm 2.14$ \\
Hct (\%) & $30.36 \pm 3.48$ \\
Albumin (g/dL) & $4.15 \pm 0.27$ \\
Calcium (mg/dL) & $8.54 \pm 0.51$ \\
Phosphate (mg/dL) & $5.32 \pm 1.11$ \\
I-PTH (pg/mL) & $335.08 \pm 187.97$ \\
Alk-P (IU/L) & $103.01 \pm 34.64$ \\
hs CRP (mg/dL) & $0.72 \pm 0.69$ \\
Free IS (mg/L) & $1.50 \pm 0.80$ \\
Total IS (mg/L) & $38.15 \pm 13.08$ \\
AGEs (AU/mL) & PCS (mg/L) \\
\hline
\end{tabular}




\section{Kidney \\ Blood Pressure Research}

Table 2. Correlations between serum indoxyl sulfate and p-cresylsulfate levels and baseline clinical and biochemical characteristics

\begin{tabular}{lcccccccc}
\hline & \multicolumn{2}{c}{ Total PCS } & \multicolumn{2}{c}{ Free PCS } & \multicolumn{2}{c}{ Total IS } & \multicolumn{2}{c}{ Free IS } \\
\cline { 2 - 9 } Variables & $\mathrm{r}$ & $p$ & $\mathrm{r}$ & $p$ & $\mathrm{r}$ & $p$ & $\mathrm{r}$ & $p$ \\
\hline Age (yrs) & 0.16 & NS & 0.14 & NS & -0.07 & NS & 0.07 & NS \\
Sex & 0.04 & NS & 0.09 & NS & 0.14 & NS & 0.08 & NS \\
DM & 0.05 & NS & 0.18 & NS & -0.09 & NS & 0.03 & NS \\
Dialysis time(m) & 0.11 & NS & 0.08 & NS & 0.21 & NS & 0.15 & NS \\
Kt/V & -0.02 & NS & -0.03 & NS & -0.04 & NS & 0.03 & NS \\
nPCR (g/kg/day) & 0.06 & NS & -0.08 & NS & 0.18 & NS & -0.05 & NS \\
Albumin (g/dL) & -0.03 & NS & -0.25 & $<0.05$ & -0.21 & $<0.05$ & -1.34 & NS \\
Hemoglobin (g/dL) & -0.02 & NS & 0.06 & NS & -0.14 & NS & 0.06 & NS \\
BUN (mg/dL) & -0.09 & NS & -0.12 & NS & -0.13 & NS & 0.03 & NS \\
Creatinine (mg/dL) & -0.14 & NS & -0.15 & NS & 0.29 & $<0.01$ & 0.07 & NS \\
Uric acid (mg/dL) & 0.01 & NS & -0.06 & NS & 0.05 & NS & -0.04 & NS \\
Na (mg/dL) & 0.05 & NS & -0.18 & NS & 0.17 & NS & 0.14 & NS \\
K (mg/dL) & 0.11 & NS & 0.03 & NS & 0.20 & $<0.01$ & 0.13 & NS \\
Calcium (mg/dL) & 0.04 & NS & -0.06 & NS & 0.01 & NS & 0.16 & NS \\
Phosphate (mg/dL) & -0.01 & NS & 0.06 & NS & 0.03 & NS & -0.05 & NS \\
Alk-p (IU/L) & -0.05 & NS & 0.16 & NS & 0.14 & NS & 0.22 & $<0.05$ \\
I-PTH (pg/mL) & 0.03 & NS & 0.12 & NS & 0.09 & NS & -0.11 & NS \\
hsCRP (mg/dL) & 0.05 & NS & 0.14 & NS & -0.06 & NS & 0.25 & $<0.05$ \\
AGEs (AU/mL) & 0.01 & NS & 0.04 & NS & 0.27 & $<0.01$ & 0.11 & NS \\
\hline & & & & & & & & \\
\hline
\end{tabular}

end-stage renal disease in the study patients included chronic glomerulonephritis $(\mathrm{n}=65$, $50.4 \%)$, diabetic nephropathy $(n=58,45.0 \%)$, polycystic kidney disease $(n=4,3.1 \%)$ and lupus nephritis $(\mathrm{n}=2,1.5 \%)$. Our subjects consisted of 66 males $(51.2 \%)$ and 63 females $(48.8 \%)$ with a mean age of $65.61 \pm 9.12$ years. The following average levels were recorded: serum free IS $1.50 \pm 0.80 \mathrm{mg} / \mathrm{L}$; total IS $38.15 \pm 13.08 \mathrm{mg} / \mathrm{L}$; free PCS $1.71 \pm 0.70 \mathrm{mg} / \mathrm{L}$; total PCS $26.03 \pm 12.01 \mathrm{mg} / \mathrm{L}$; and AGEs $12.6 \pm 6.2 \mathrm{AU} / \mathrm{mL}$.

\section{Correlations Between AGEs and Clinical Variables}

Table 2 shows the correlations between IS, PCS and independent variables. Total IS was significantly associated with serum albumin ( $\mathrm{r}=-0.21, \mathrm{p}<0.05), \mathrm{Cr}(\mathrm{r}=0.29, \mathrm{p}<0.01), \mathrm{K}(\mathrm{r}$ $=0.20, \mathrm{p}<0.01)$ and AGEs $(\mathrm{r}=0.27, \mathrm{p}<0.01)$. Free IS was positively correlated with alkaline phosphatase $(r=0.22, p<0.05)$ and hsCRP $(r=0.25, p<0.05)$. Free PCS was negatively related to albumin levels $(r=-0.25, p<0.05)$. However, there was no significant correlation between total PCS and clinical biochemical parameters. Table 3 shows the results of multiple variable analysis using stepwise linear regression for total IS as a dependent variable. The independent variables in the model included gender, age, diabetes, duration of $\mathrm{HD}, \mathrm{Kt} / \mathrm{V}, \mathrm{Cr}$, albumin, phosphate, i-PTH, AGEs, free IS and total PCS. Total IS was significantly associated with AGEs $(\mathrm{p}<0.01)$, free IS $(\mathrm{p}<0.01)$ and $\mathrm{Cr}(\mathrm{p}<0.01)$. Table 4 shows the multiple variables analysis with AGEs as a dependent variable. The independent variables in the model included gender, age, diabetes, duration of HD, Kt/V, Cr, hsCRP, albumin, calcium, phosphate, i-PTH, total IS, free IS, total PCS and free PCS. Serum AGEs levels were strongly correlated with diabetes $(\mathrm{p}<0.01)$ and total IS $(\mathrm{p}<0.01)$ after adjusting for other confounding factors. 


\section{Kidney Blood Pressure Research}

Figure 1 demonstrates the correlation between AGE levels and proteinbound uremic toxins. There was no significant association between AGEs and total PCS, free PCS and free IS, except total IS ( $\mathrm{r}$ $=0.27, \mathrm{p}<0.01$ ). Figure 2 shows the serum IS level (30.7 $\mathrm{mg} / \mathrm{L})$ predicted by the ROC curve. All patients were divided into two groups (high and low) based on IS level (30.7 $\mathrm{mg} / \mathrm{L}$ ). Patients in the high IS group had higher nPCR $(\mathrm{p}=0.04), \operatorname{Cr}(\mathrm{p}<0.01)$, i-PTH (p = 0.03) and AGE concentrations $(p<0.01)$ compared to the low IS group (Table 5). However, the serum AGE levels were higher in patients with diabetes than patients without diabetes (Figure 3).

\section{Discussion}

Our study demonstrated a positive association between IS and AGEs. Serum IS, but not PCS, was independently correlated with AGEs after adjusting for other independent parameters in patients on HD. Our results suggest that IS is an essential factor in the development of atherosclerosis.

CVD is the primary cause of morbidity and mortality in CKD patients [2, 3]. Some biomarkers, including protein-bound uremic toxins and AGEs, are the focus of research to elucidate the mechanisms of high cardiovascular risk in CKD patients [7-10,18]. Serum IS originates from the gastrointestinal tract, and it is elevated in CKD patients [19, 20]. IS may lead to renal function deterioration because of increased renal fibrosis gene expression and stimulation of kidney tubulointerstitial fibrosis and glomerular sclerosis [21, 22]. IS also inhibits endothelial cell proliferation and plays a vital role in endothelial dysfunction via oxidative stress induction $[4,5]$. Therefore, these findings suggest that IS is a nephrotoxin and a vascular toxin.

AGEs are also increased in situations of hyperglycemia and oxidative stress, such as diabetes, and AGEs are products of non-enzymatic glycation and protein and lipid oxidation $[11,12]$. Serum AGE concentrations are significantly increased in CKD patients, including pre-dialysis and HD patients, compared to healthy controls $[13,14]$. One previous study demonstrated that serum $\mathrm{N}^{\varepsilon}$-carboxymethyllysine (CML) predicted left ventricular hypertrophy in CKD patients, and it was a strong predictor of mortality [23].AGEs are also noted in atherosclerotic plaques, and increased AGEs levels are related to coronary calcification in HD patients [24]. One clinical study demonstrated that high serum CML levels were predictive of all-cause mortality in a cohort of 154 maintenance HD patients [25]. Autofluorescence of the skin was also reported as a valuable predictor of mortality in uremia [26]. These studies

Table 3. Stepwise multiple linear regression analysis for total indoxyl

Table 4. Stepwise multiple linear regression analysis for AGEs as a dependent variable

\begin{tabular}{lcccc}
\hline & \multicolumn{2}{c}{$\begin{array}{c}\text { Unstandardized } \\
\text { coefficients }\end{array}$} & \multicolumn{2}{c}{$\begin{array}{c}\text { Standardized } \\
\text { coefficients }\end{array}$} \\
\cline { 2 - 5 } Variables & $\mathrm{B}$ & Std. Error & Std. Error & $p$ value \\
\hline DM & 3.672 & 1.545 & 0.250 & 0.01 \\
Total IS & 0.200 & 0.058 & 0.341 & $<0.01$ \\
\hline
\end{tabular}

This model included gender, age, DM, duration on hemodialysis, $\mathrm{Kt} / \mathrm{V}, \mathrm{Cr}$, hsCRP, albumin, Ca, P, i-PTH, total IS, free IS, total PCS and free PCS. 


\section{Kidney \\ Blood Pressure Research}

Kidney Blood Press Res 2015;40:121-129

\begin{tabular}{l|l}
\hline DOI: $10.1159 / 000368488$ & (c) 2015 S. Karger AG, Basel
\end{tabular}

Published online: March 19, 2015

www.karger.com/kbr
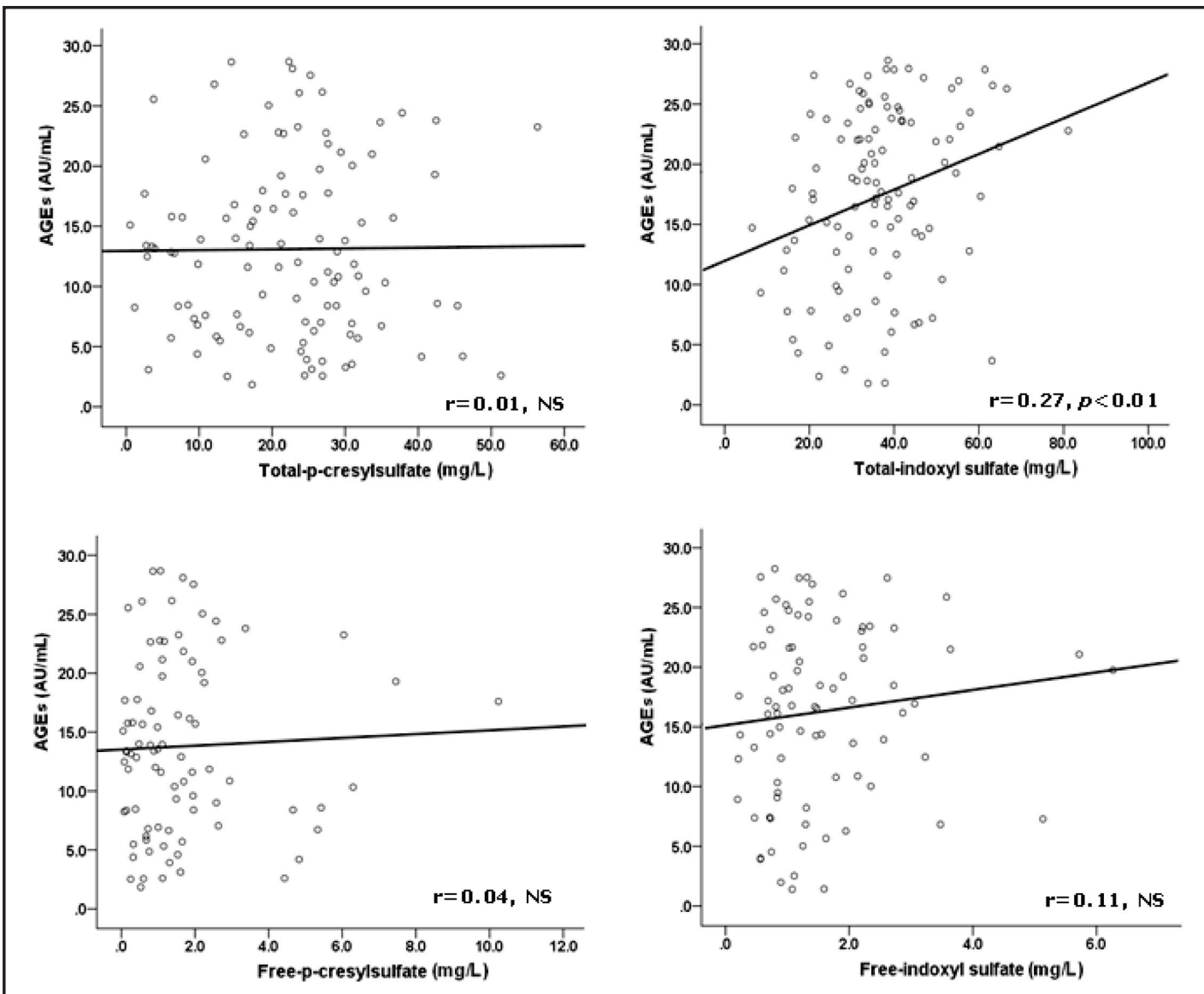

Fig. 1. Correlations between AGEs and (A) total PCS, (B) total IS (C) free PCS and (D) free IS in HD patients.

suggest that the accumulation of AGEs is related to a poor cardiovascular or renal outcome in CKD patients.

However, the correlation of IS or PCS with AGEs formation was not fully clear previously. This study examined the relationships of two novel survival and vascular markers with AGEs in a human cohort. Our results demonstrated that only total IS levels were significantly associated with serum AGEs concentrations after adjusting for other confounding factors. Our results are consistent with Taki et al. who evaluated the relationships between IS and pentosidine in patients on HD [27]. This study showed that IS was independently related to pentosidine levels, and the results suggested that IS is involved in the pathogenesis of atherosclerosis. Recent studies also indicated that elevated IS and PCS levels are associated with more frequent vascular access failure and dysfunction in HD patients [28, 29]. However, the present report is the first study

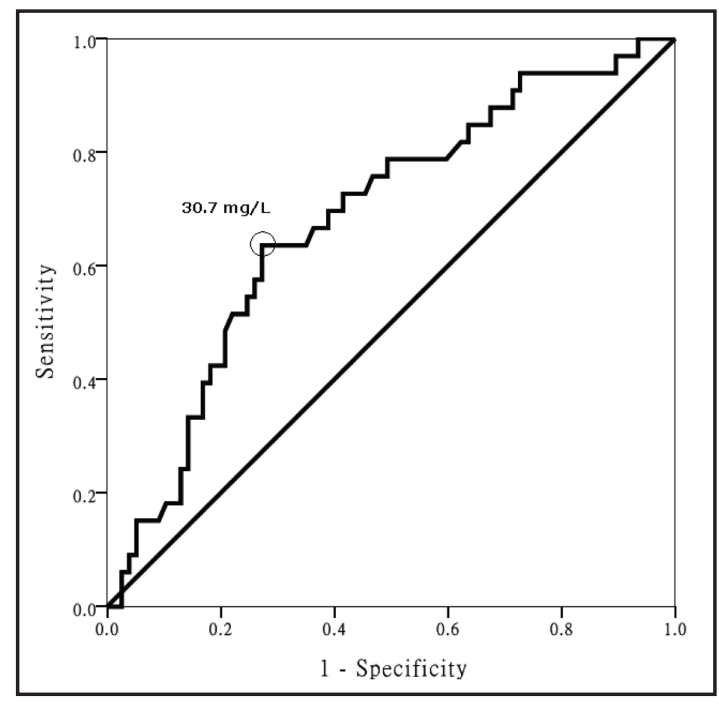

Fig. 2. Receiver-operating characteristic (ROC) curve of weight for predicting the serum indoxyl sulfate levels. The optimum cut-off point (open circle) was defined as the closest point on the ROC curve to the point $(X, Y)=(0,1)$, where $X=1-$ specificity and $Y=$ sensitivity. 


\section{Kidney \\ Blood Pressure Research}

to explore the association of two kinds of protein-bound uremic toxins, IS and PCS, concurrently with AGEs and other clinical independent variables. The relationships between IS and AGEs were confirmed with different modes of multivariate analysis. Why does IS, but not PCS, significantly correlated with AGEs? IS and PCS belong to the same group of gastrointestinal tract-related uremic toxins, but the effect of PCS was attenuated in our statistical analyses. IS and PCS have different pathogenetic mechanisms, but they share some similarities. A recent systemic review of in vitro studies also confirmed the roles of IS and PCS in vascular disease and kidney disease progression [30]. Nevertheless, we cannot completely exclude the possible role of PCS in the development of atherosclerosis because the environment in uremia is rather complicated, and other unidentified factors may affect the interaction between IS and PCS. Our results provide a possible correlation between protein-bound uremic toxins and AGEs from a clinical perspective. The specific relationships between IS and AGEs require verification in further studies.

\section{Conclusion}

There are several limitations to our study. First, the sample size was small, and all subjects were enrolled from one medical center. Second, we were unable to determine the possible causes of the disparity in the relationship between IS and PCS with AGEs. Third, this study was a cross-sectional study, and we could not further discover the defined interaction mechanisms between IS and AGEs. Finally, whether the relationships between IS, PCS and AGEs change after the administration of AST-120 [31], which is an activated charcoal absorbent that

Table 5. The comparisons of independent variables in HD patients stratified by indoxyl sulfate levels

\begin{tabular}{|c|c|c|c|}
\hline Variables & $\begin{array}{c}\text { High } \\
\text { Indoxyl sulfate } \\
>30.7 \mathrm{mg} / \mathrm{L}\end{array}$ & $\begin{array}{c}\text { Low } \\
\text { Indoxyl sulfate } \\
\leqq 30.7 \mathrm{mg} / \mathrm{L}\end{array}$ & $p$-value \\
\hline Median age $(y)$ & $58.31 \pm 11.7$ & $62.15 \pm 11.9$ & NS \\
\hline Time of HD (m) & $43.13 \pm 22.43$ & $41.98 \pm 21.54$ & NS \\
\hline Diabetes & $45.4 \%$ & $57.6 \%$ & NS \\
\hline nPCR (g/kg/day) & $1.16 \pm 0.25$ & $1.03 \pm 0.28$ & 0.040 \\
\hline $\mathrm{Kt} / \mathrm{V}$ & $1.42 \pm 0.27$ & $1.41 \pm 0.24$ & NS \\
\hline $\mathrm{CO} 2(\mathrm{mmol} / \mathrm{L})$ & $22.37 \pm 1.98$ & $23.72 \pm 2.01$ & NS \\
\hline $\mathrm{Hb}(\mathrm{g} / \mathrm{dL})$ & $10.41 \pm 1.33$ & $10.88 \pm 1.54$ & NS \\
\hline Creatinine (mg/dl) & $10.98 \pm 2.14$ & $9.33 \pm 2.38$ & $<0.01$ \\
\hline Albumin (g/dL) & $4.17 \pm 0.31$ & $3.97 \pm 0.32$ & 0.01 \\
\hline Calcium (mg/dL) & $9.26 \pm 0.73$ & $9.27 \pm 0.80$ & NS \\
\hline Phosphate (mg/dL) & $5.51 \pm 1.53$ & $5.19 \pm 1.38$ & NS \\
\hline I-PTH (pg/mL) & $381.92 \pm 298.47$ & $264.33 \pm 220.61$ & 0.03 \\
\hline Alk-P (IU/L) & $104.83 \pm 52.05$ & $101.42 \pm 37.77$ & NS \\
\hline hs CRP (mg/dL) & $1.51 \pm$ & $0.82 \pm$ & NS \\
\hline Free PCS (mg/L) & $1.56 \pm 1.51$ & $1.86 \pm 2.23$ & NS \\
\hline Total PCS (mg/L) & $22.68 \pm 11.81$ & $20.42 \pm 10.53$ & NS \\
\hline AGEs (AU/ml) & $16.3 \pm 6.9$ & $11.7 \pm 7.0$ & $<0.01$ \\
\hline
\end{tabular}

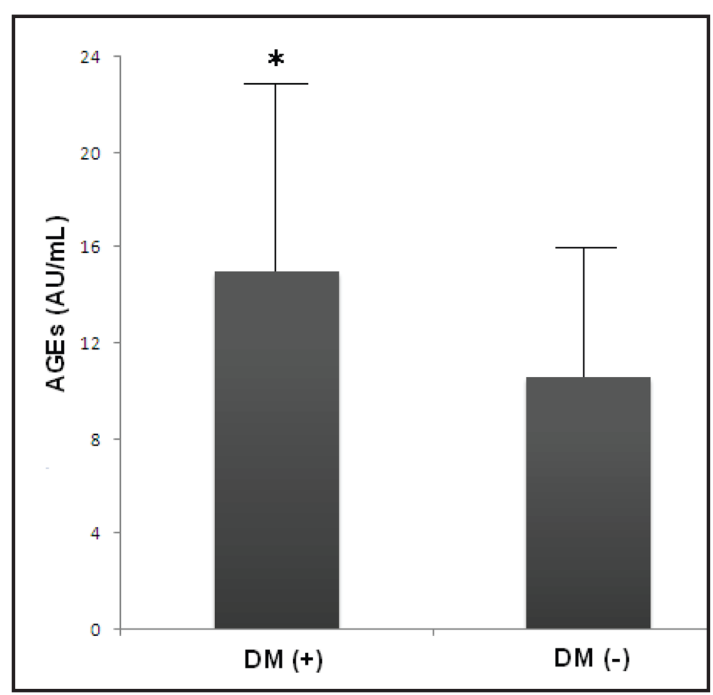

Fig. 3. The comparison of serum AGEs levels in HD patient with and without $\mathrm{DM},{ }^{*} \mathrm{p}<0.01$. 


\section{Kidney \\ Blood Pressure Research}

Kidney Blood Press Res 2015;40:121-129

\begin{tabular}{l|l}
\hline DOI: $10.1159 / 000368488$ & (C) 2015 S. Karger AG, Basel
\end{tabular}

Published online: March 19, 2015

www.karger.com/kbr

Lin/Lin/Pan/Chuang/Liu/Sun/Wang/Chen/Wu: Indoxyl Sulfate Relationship to AGEs in HD Patients

reduces serum IS levels and delays kidney progression, are not known. Therefore, additional prospective investigations are required to elucidate the answers to these questions.

In summary, IS and PCS are novel and vital non-traditional risk factors that are associated with adverse clinical outcomes. AGEs, pro-inflammatory and pro-oxidative compounds accumulate in CKD patients, and these factors play an essential role in endothelial dysfunction and atherosclerosis. Our study evaluated the correlation of two gastrointestinal tract-related uremic toxins with AGEs and other biochemical parameters in an HD cohort. Our results showed that serum IS levels, but not PCS levels, were positively related to AGE concentrations. Serum IS levels were also independently correlated with AGEs after adjusting for other independent confounding factors. Our results suggest that IS is an essential factor in the development of atherosclerosis. Further prospective trials are required to elucidate the definite interaction mechanism between IS and AGEs.

\section{Disclosure Statement}

The authors of this manuscript state that they do not have any conflict of interests and nothing to disclose.

\section{Acknowledgment}

We would like to thank all of the patients who were involved in this study. This study was supported in part by a Grant from Taiwan National Science Council (NSC 102-2314-B195-004) and Mackay Memorial Hospital (MMH-103-12).

\section{References}

1 Vanholder R, Baurmeister U, Brunet P, Cohen G, Glorieux G, Jankowski J, European Uremic Toxin Work Group: A bench to bedside view of uremic toxins. J Am Soc Nephrol 2008;19:863-870.

2 Levin A, Foley RN: Cardiovascular disease in chronic renal insufficiency. Am J Kidney Dis 2000;36:S1-S12.

3 Keith DS, Nichols GA, Gullion CM, Brown JB, Smith DH: Longitudinal follow-up and outcomes among a population with chronic kidney disease in a large managed care organization. Arch Intern Med 2004;164:659-663.

4 Dou L, Bertrand E, Cerini C, Faure V, Sampol J, Vanholder R, Berland Y, Brunet P: The uremic solutes p-cresol and indoxyl sulfate inhibit endothelial proliferation and wound repair. Kidney Int 2004;65:442-451.

5 Yu M, Kim YJ, Kang DH: Indoxyl sulfate-induced endothelial dysfunction in patients with chronic kidney disease via an induction of oxidative stress. Clin J Am Soc Nephrol 2011;6:30-39.

6 Tumur Z, Niwa T: Indoxyl sulfate inhibits nitric oxide production and cell viability by inducing oxidative stress in vascular endothelial cells. Am J Nephrol 2009;29:551-557.

7 Lin CJ, Wu CJ, Pan CF, Chen YC, Sun FJ, Chen HH: Serum protein-bound uraemic toxins and clinical outcomes in haemodialysis patients. Nephrol Dial Transplant 2010;25:3693-3700.

8 Bammens B, Evenepoel P, Keuleers H, Verbeke K, Vanrenterghem Y: Free serum concentrations of the protein-bound retention solute p-cresol predict mortality in hemodialysis patients. Kidney Int 2006;69:10811087.

9 Meijers BK, Bammens B, De Moor B, Verbeke K, Vanrenterghem Y, Evenepoel P: Free p-cresol is associated with cardiovascular disease in hemodialysis patients. Kidney Int 2008;73:1174-1180.

10 Barreto FC, Barreto DV, Liabeuf S, Meert N, Glorieux G, Temmar M, Choukroun G, Vanholder R, Massy ZA; European Uremic Toxin Work Group (EUTox): Serum indoxyl sulfate is associated with vascular disease and mortality in chronic kidney disease patients. Clin J Am Soc Nephrol 2009;4:1551-1558. 


\section{Kidney \\ Blood Pressure Research}

Kidney Blood Press Res 2015;40:121-129

\begin{tabular}{l|l}
\hline DOI: $10.1159 / 000368488$ & (C) 2015 S. Karger AG, Basel
\end{tabular}

Published online: March 19, 2015

www.karger.com/kbr

11 Wells-Knecht KJ, Brinkmann E, Wells-Knecht MC, Litchfield JE, Ahmed MU, Reddy S, Zyzak DV, Thorpe SR, Baynes JW: New biomarkers of Maillard reaction damage to proteins. Nephrol Dial Transplant 1996;11:4147.

12 Thorpe SR, Baynes JW: Maillard reaction products in tissue proteins: new products and new perspectives. Amino Acids 2003;25:275-281.

13 Busch M, Franke S, Müller A, Wolf M, Gerth J, Ott U, Niwa T, Stein G: Potential cardiovascular risk factors in chronic kidney disease: AGEs, total homocysteine and metabolites, and the C-reactive protein. Kidney Int 2004;66:338-347.

14 Semba RD, Ferrucci L, Fink JC, Sun K, Beck J, Dalal M, Guralnik JM, Fried LP: Advanced glycation end products and their circulating receptors and level of kidney function in older community-dwelling women. Am J Kidney Dis 2009;53:51-58 .

15 Goldin A, Beckman JA, Schmidt AM, Creager MA: Advanced glycation end products : Sparking the development of diabetic vascular injury. Circulation 2006;114:597-605.

16 Park L, Raman KG, Lee KJ, Lu Y, Ferran LJ Jr, Chow WS, Stern D, Schmidt AM: Suppression of accelerated diabetic atherosclerosis by the soluble receptor for advanced glycation endproducts. Nat Med 1998;4:10251031.

17 Daugirdas JT: The post:pre-dialysis plasma urea nitrogen ratio to estimate Kt/V and nPCR: mathematical modeling. Int J Artif Organs 1989;12:411-419.

18 Meerwaldt R, Zeebregts CJ, Navis G, Hillebrands JL, Lefrandt JD, Smit AJ: Accumulation of advanced glycation end products and chronic complications in ESRD treated by dialysis. Am J Kidney Dis 2009;53:138-150.

19 Liabeuf S, Barreto DV, Barreto FC, Meert N, Glorieux G, Schepers E, Temmar M, Choukroun G, Vanholder R, Massy ZA, European Uraemic Toxin Work Group (EUTox): Free p-cresylsulphate is a predictor of mortality in patients at different stages of chronic kidney disease. Nephrol Dial Transplant 2010;25:1183-1191.

20 Lin CJ, Chen HH, Pan CF, Chuang CK, Wang TJ, Sun FJ, Wu CJ: p-Cresylsulfate and indoxyl sulfate level at different stages of chronic kidney disease. J Clin Lab Anal 2011;25:191-197.

21 Miyazaki T, Ise M, Hirata M, Endo K, Ito Y, Seo H, Niwa T: Indoxyl sulfate stimulates renal synthesis of transforming growth factor-beta 1 and progression of renal failure. Kidney Int Suppl 1997;63:S211-S214.

22 Miyazaki T, Ise M, Seo H, Niwa T: Indoxyl sulfate increases the gene expressions of TGF-beta 1, TIMP-1 and pro-alpha 1(I) collagen in uremic rat kidneys. Kidney Int Suppl 1997;62:S15-S22.

23 Stein G, Busch M, Müller A, Wendt T, Franke C, Niwa T, Franke S: Are advanced glycation end products cardiovascular risk factors in patients with CRF? Am J Kidney Dis 2003;41:S52-S56.

24 Taki K, Takayama F, Tsuruta Y, Niwa T: Oxidative stress, advanced glycation end product, and coronary artery calcification in hemodialysis patients. Kidney Int 2006;70:218-224.

25 Wagner Z, Molnár M, Molnár GA, Tamaskó M, Laczy B, Wagner L, Csiky B, Heidland A, Nagy J, Wittmann I: Serum carboxymethyllysine predicts mortality in hemodialysis patients. Am J Kidney Dis 2006;47:294-300.

26 Meerwaldt R, Hartog JW, Graaff R, Huisman RJ, Links TP, den Hollander NC, Thorpe SR, Baynes JW, Navis G, Gans RO, Smit AJ: Skin autofluorescence, a measure of cumulative metabolic stress and advanced glycation end products, predicts mortality in hemodialysis patients. J Am Soc Nephrol 2005;16:3687-3693.

27 Taki K, Tsuruta Y, Niwa T: Indoxyl sulfate and atherosclerotic risk factors in hemodialysis patients. Am J Nephrol 2007;27:30-35.

28 Chen TC, Wang CY, Hsu CY, Wu CH, Kuo CC, Wang KC, Yang CC, Wu MT, Chuang FR, Lee CT: Free p-cresol sulfate is associated with survival and function of vascular access in chronic hemodialysis patients. Kidney Blood Press Res 2012;35:583-588.

29 Lin CJ, Chi-Feng Pan CF, Liu HL, Chuang CK, Jayakumar T, Wang TJ, Chen HH, Wu CJ: The role of protein-bound uremic toxins on peripheral artery disease and vascular access failure in patients on hemodialysis. Atherosclerosis 2012;225:173-179.

30 Vanholder R, Schepers E, Pletinck A, Nagler EV, Glorieux G. The uremic toxicity of indoxyl sulfate and p-cresyl sulfate: a systematic review. J Am Soc Nephrol 2014;25:1897-907.

31 Schulman G, Agarwal R, Acharya M, Berl T, Blumenthal S, Kopyt N: A multicenter, randomized, double blind, placebo controlled, dose ranging study of AST-120 (Kremezin) in patients with moderate to severe CKD. Am J Kidney Dis 2006;47:565-577. 